\title{
Quantificação e distribuição de células argirófilas e argentafins no estômago de suínos com e sem úlcera gástrica
}

\section{Quantification and distribution of argirophils and argentafins cells in swine stomach with and without gastric ulcer}

\author{
João Carlos Pereira da Silva, ${ }^{*}$ José Lúcio dos Santos, ${ }^{\star \star}$ Alfredo José Afonso Barbosa ${ }^{\star \star \star}$
}

\begin{abstract}
Resumo
Com a finalidade de se conhecer a distribuição e o número das células endócrinas do estômago de suínos com e sem úlcera gástrica da pars oesophagea procedeu-se ao presente trabalho. Os estômagos de 32 suínos adultos, com mucosa gástrica macroscopicamente normal e de outros $32 \mathrm{com}$ úlcera gástrica da pars oesophagea, foram colhidos após o abate. Fragmentos de regiões padronizadas da mucosa antral $(n=2)$, mucosa oxíntica $(n=2)$ e cárdica $(n=2)$ foram fixados em Bouin e incluídos em parafina. Células argirófilas e argentafins foram demonstradas pelos métodos de Grimelius e Masson-Fontana, respectivamente, quantificadas e analisadas quanto à distribuição nos diferentes tipos de mucosa. Nos animais estudados as células argirófilas foram mais frequentes na mucosa oxíntica, em relação às mucosas antral e cárdica. Por sua vez, as células argentafins foram mais frequentes na mucosa antral do que na mucosa oxíntica $(P<0,05)$. Não ocorreram diferenças quanto a distribuição e quanto ao número de células argirófilas e argentafins entre os dois grupos de animais estudados, com e sem úlcera gástrica.
\end{abstract}

Palavras-chave: suíno, úlcera gástrica, células argirófilas e argentafins

\begin{abstract}
With the purpose of knowing the distribution and the number of the endocrine cells of the swine stomach with and without gastric ulcer of pars oesophagea it was proceeded the present work. The stomachs of 32 adult swines, with macroscopically normal gastric mucosa and of others 32 with gastric ulcer of pars oesophagea, had been harvested after abate it. Fragments of standardized regions of the antral mucosa $(n=2)$, oxyntic mucosa $(n=2)$ and cardiac $(n=2)$ had been fixed in Bouin and included in paraffin. Argyrofils and argentafins cells had been demonstrated by the methods of Grimelius and Masson-Fontana, respectively, quantified and analyzed as for the distribution in the different types of mucosa. In the studied animals the cells argyrofils had been more frequent in the oxyntic mucosa, in relation to the antral and cardiac mucosa. In turn, the argentafins cells had been more frequent in the antral mucosa instead of the oxyntic mucosa $(P<0,05)$. differences had not occurred as far the distribution and as far the frame number argyrofils and argentafins between the two groups of studied animals, with and without gastric ulcer.
\end{abstract}

Keywords: swine; gastric ulcer; argyrofils and argentafins cells.

\section{Introdução}

$\mathrm{Na}$ espécie humana, existem numerosos trabalhos que relacionam a alteração da densidade de células endócrinas do estômago com doenças gastroduodenais, sobretudo com a gastrite crônica e com a úlcera péptica duodenal (Friersen et al.,1972; Polak et al.,1972; Stave e Brandtzaeg,1976; Torres et al.,1986; Crivelli et al.,1977; Bordi et al.,1989; Eissele et al.,1997; Maaroos et al.,1998; Omura et al., 1998). A principal justificativa para estes estudos advém das estreitas relações dos elementos endócrinos do estômago com a secreção ácido-péptica, considerada fator essencial na gênese da úlcera gastroduodenal.
Por outro lado, no contexto da medicina veterinária, os trabaIhos enfocando as células endócrinas do estômago em diferentes animais não estabelecem qualquer relação com doenças gástricas de ocorrência natural, ligadas a possíveis distúrbios da secreção ácido-péptica, ficando restritos a abordagens relacionadas com a quantificação e distribuição de diferentes tipos de células endócrinas ao longo da mucosa gástrica (Kitamura et al.,1982; Alumets et al.,1983; Calingasan et al.,1984; Kitamura et al.,1984; Kitamura et al.,1985 e Ito et al.,1987).

Portanto, justificam-se estudos visando o melhor conhecimento sobre a dinâmica do compartimento endócrino do

\footnotetext{
*. Médico Veterinário-Doutor-Professor Titular do Departamento de Veterinária da UFV - Viçosa, MG, CEP 36571-000. Autor para correspondência. E-mail: jcpsilva@mail.ufv.br

** Médico Veterinário-Doutor-Professor Adjunto do Departamento de Veterinária da UFV - Viçosa, MG, CEP 36571-000.

*** Médico-Doutor-Professor Titular da Faculdade de Medicina da UFMG - Belo Horizonte, MG.
} 
estômago nos animais domésticos, associando-os às doenças gastroduodenais. Nesse contexto destacam-se os suínos pela alta frequência da úlcera gástrica, considerada como de natureza ácidó-péptica (HUBER e WALLIN,1965; MAHAN et al.,1966; HUBBER e WALLIN,1967; MAXWELL et al.,1970; e KOKUE et al.,1981). Com este objetivo, propõe-se aqui estudar o número e a distribuição das células argirófilas e argentafins nos diferentes tipos de mucosa gástrica de suínos com e sem úlcera da pars oesophagea.

\section{Materiais e métodos}

Foram utilizados 64 suínos mestiços, de ambos os sexos, do tipo carne, com aproximadamente cinco meses de idade e oriundos de criação intensiva da Universidade Federal de Viçosa. Após o abate dos animais, os estômagos foram separados das carcaças, abertos ao longo da curvatura maior, esvaziado de seu conteúdo, cuidadosamente lavado para retirar o excesso de muco, seguindo-se de imediato exame macroscópico da peça. Os estômagos foram então identificados e, baseado na presença ou ausência de úlcera na pars oesophagea, foram divididos em dois grupos; Grupo 1Formado por 32 estômagos com a mucosa da pars oesophagea aparentemente normal; Grupo 2- Formado por 32 estômagos com úlceras de, pelo menos, $2 \mathrm{~cm}$ em seu diâmetro maior.

Para processamento histológico foram colhidos fragmentos ao longo das pequena e grande curvaturas, abrangendo as diferentes regiões do estômago, seguindo-se rigorosamente a um mapeamento prévio. Os fragmentos foram fixados em líquido de Bouin por 24 horas, e processados rotineiramente por inclusão em parafina.

Para evidenciar células argirófilas e argentafins foram realizadas colorações histoquímicas pela prata, utilizando-se, respectivamente, as técnicas de Grimelius (Grimelius,1968) e de Masson-Fontana modificada (Barbosa et al., 1984). O estudo das células argirófilas foi realizado em duas áreas, distal e proximal, da região cárdia e oxíntica. Em relação à mucosa antral utilizaram-se fragmentos da região medial e da região proximal. Para o estudo das células argentafins foram também utilizados dois fragmentos da mucosa do corpo e dois fragmentos do antro gástrico, excluindo a mucosa da cárdia em virtude do reduzido número dessas células nesta região observado após estudos preliminares. Nos cortes histológicos de cada fragmento foram contadas as células endócrinas em 10 campos microscópicos (x 400) consecutivos da metade basal da mucosa (cada campo tangenciando a muscular da mucosa) e outros 10 campos consecutivos da metade superficial da mucosa (cada campo tangenciando 0 epitélio de revestimento da mucosa). Geralmente a espessura da mucosa antral e oxíntica comportava, sem sobreposição, os dois campos microscópicos utilizados. Os resultados foram expressos em número médio de células por $\mathrm{mm}^{2}$.

Tendo em vista ser a mucosa do cárdia mais delgada (espessura ligeiramente superior ao diâmetro de um campo microscópico), nesta região contou-se o número de células presentes em 10 campos consecutivos. Após a contagem procedeu-se ao cálculo do número de células por $\mathrm{mm}^{2}$.

Para estabelecer o grau de diferença entre as variáveis foi utilizado o Teste " $t$ " de Student ao nível de significância de $5 \%(p<0,05)$.

\section{Resultados}

$\mathrm{Na}$ mucosa cárdica, a média de células argirófilas por $\mathrm{mm}^{2}$ foi de $33,28 \pm 12,52$ nos suínos com úlcera, e de $28,93 \pm 13,28$ nos controles. Nesta região, as células argirófilas, além de escassas, mostraram um padrão de distribuição mais irregular (Figura 1a), muitas vezes formando agrupamentos na periferia de nódulos linfáticos. Na mucosa oxíntica, o número de células argirófilas por $\mathrm{mm}^{2}$ foi de $205,56 \pm 47,57$ no grupo com úlcera, e 212,73 $\pm 43,86$ no grupo controle. Nessa mucosa, as células Grimelius-positivas foram muito numerosas e se distribuíam de forma regular e difusa, podendo ser visualizadas por toda a espessura da mucosa (Figura 1b). No antro, o número médio de células argirófilas por $\mathrm{mm}^{2}$ foi de $69,32 \pm 24,93$ no grupo de suínos com úlcera, e $72,67 \pm 21,69$ no grupo controle. Nesta região, as células argirófilas distribuíam-se regularmente, de forma difusa, tendendo a se localizar principalmente no terço médio das glândulas pilóricas (Figura 1c). O número médio de células argirófilas nas diferentes mucosas glandulares do estômago de suínos com e sem úlcera gástrica encontra-se na Tabela 1.

Quanto às células argentafins, o número médio das mesmas por $\mathrm{mm}^{2}$, na mucosa oxíntica, foi de $14,64 \pm 5,41$ no grupo com úlcera, e de 15,99 $\pm 5,58$ células nos suínos controles. Nesse caso, as células Masson-Fontana positivas, além de pouco numerosas, possuíam distribuição irregular tendendo a se agruparem próximo à base das glândulas fúndicas ( $\mathrm{Fi}$ gura 2a).

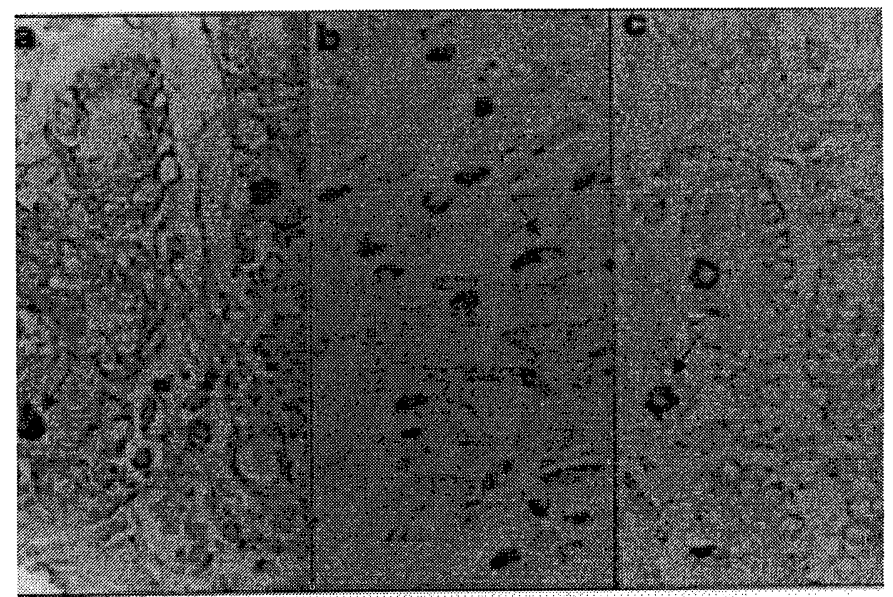

Figura 1 - Estômago de suíno - Células argirófilas (setas) nas mucosas cárdica (a), oxíntica (b) e antral (c). Técnica de Grimelius 1260X.

Tabela 1 - Número médio de células argirófilas por $\mathrm{mm}^{2}$ nas mucosas do antro, do corpo e da cárdia de suínos com e sem úlcera gástrica

\begin{tabular}{lccc}
\hline GruposiVariáveis & Antro & Corpo & Cárdia \\
\hline Suínos sem úlcera & $72,67 \pm 21,75^{\mathrm{Aa}}$ & $212,73 \pm 43,86^{\mathrm{Ba}}$ & $28,93 \pm 13,28^{\mathrm{Ca}}$ \\
& & & \\
Suínos com úlcera & $69,32 \pm 24,93^{\mathrm{Aa}}$ & $205,56 \pm 47,57^{\mathrm{Ba}}$ & $33,28_{ \pm} 12,52^{\mathrm{Ca}}$ \\
\hline
\end{tabular}

Letras maiúsculas comparam médias entre colunas e letras minúsculas comparam médias entre linhas. 
Já o antro exibiu um número médio de células, por $\mathrm{mm}^{2}$, de $29,75 \pm 12,17$ nos suínos com úlcera, e de $29,10 \pm 11,93$ nos sem úlcera. Nesta região, essas células endócrinas distribuíam-se de forma irregular, tendendo a se agruparem preferencialmente no terço médio das glândulas pilóricas (Figura 2b).

Os dados relativos ao número médio de células argentafins, nas mucosas do antro e do corpo, de suínos com e sem úlcera gástrica encontram-se compilados na Tabela. 2.

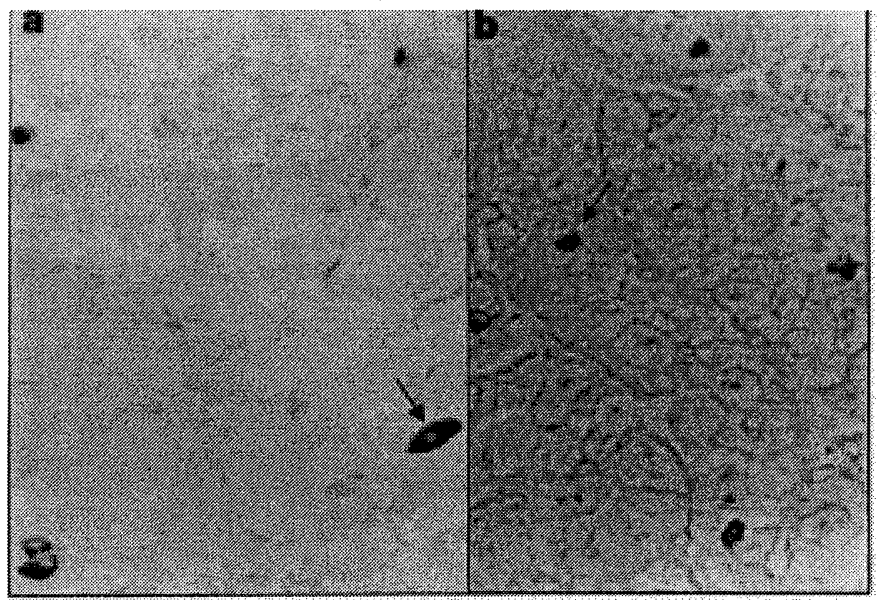

Figura 2 - Estômago de suíno - Células argentafins (setas) nas mucosas oxíntica (a) e antral (b). Técnica de Masson-Fontana modificada. $1260 \mathrm{X}$.

Tabela 2 - Número médio de células argentafins por $\mathrm{mm}^{2}$ nas mucosas do antro e do corpo gástrico de suínos com e sem úlcera

\begin{tabular}{lrr}
\hline Gruposivariáveis & Antro & Corpo \\
\hline Suínos sem úlcera & $29,10 \pm 11,93^{\mathrm{Aa}}$ & $15,99 \pm 5,58^{\mathrm{Ba}}$ \\
Suínos com úlcera & $29,75 \pm 12,17^{\mathrm{Aa}}$ & $14,64 \pm 5,41^{\mathrm{Ba}}$ \\
\hline
\end{tabular}

Letras maiúsculas comparam médias entre colunas e letras minúsculas comparam médias entre linhas.

\section{Discussão}

Em vários animais até agora estudados quanto ao número de células endócrinas na mucosa gástrica, verifica-se uma população relativamente rica tanto na região antral (Calingasan et al.,1984; Kitamura et al., 1984; Kitamura et al.,1985; Ito et al., 1987) como na região do corpo (Kitamura et al., 1982). No rato, a rica população de células argirófilas no corpo gástrico, constituídas principalmente pelas células Enterochromaffin-like (ECL) (Inokuchi et al.,1982), supera em número as células endócrinas do antro, semelhante ao observado no suíno. Por outro lado, diferentemente de outros animais estudados, o suíno apresenta mucosa cárdica glandular bastante desenvolvida, que ocupa extensa área. Embora extensa, temos observado que a mucosa cárdica do suíno apresenta número de células endócrinas relativamente pequeno, sendo quase todas argirófilas. Uma vez que o componente endócrino da mucosa cárdica no homem e em outros animais apresenta funções desconhecidas, era de se esperar que a extensa mucosa cárdica do suíno pudesse apresentar características peculiares do componente endócrino que pudessem ajudar na compreensão de suas funções.
No suíno as células argirófilas são em maior número na mucosa oxíntica, do que na mucosa antral e na mucosa cárdica. Esse padrão de distribuição coincide, em linhas gerais, com os descritos em outros animais domésticos como o gato (Kitamura et al., 1982) e a vaca (Kitamura et al., 1985). ITO et al. (1987) verificaram, através da imunocitoquímica, a distribuição de diferentes tipos de células endócrinas no trato gastrintestinal de suínos. Contudo, os autores além de não utilizarem coloração histoquímica para identificação de células argirófilas e argentafins, amostraram apenas três fragmentos de todo o estômago, onde descreveram a presença de células produtoras de gastrina, de somatotastina, de 5-hydroxytryptamine (5HT) e de methionine-enkephalin Arg-Gly-Leu (M-ENK-8).

Ao contrário do que ocorre no homem, onde existe clara relação entre a alteração da densidade de células endócrinas e a presença de gastrite crônica e úlcera péptica duodenal (Polak et al., 1972; Torres et al., 1986; Bordi et al., 1986; Eissele et al., 1997; Maaroos et al., 1998; Omura et al., 1998), o estudo comparativo entre o número de células argirófilas do estômago de suínos com e sem úlcera gástrica não mostrou diferenças significativas. Isso poderia indicar que eventuais alterações quantitativas na produção de hormônios nos suínos com ulceração gástrica poderiam estar relacionadas com alteração da atividade funcional e não com a alteração numérica das células que os produzem. Todavia, esses dados não puderam ser confrontados, uma vez que nenhum estudo comparativo similar realizado em suínos ou em outro animal doméstico, pôde ser levantado na literatura. Aliás, a maioria dos estudos enfocando a população de células endócrinas gastrintestinais foi realizada em animais de laboratório ou em condições experimentais. O estudo da distribuição das células argirófilas na espessura das diferentes mucosas mostra que a densidade dessas células foi significativamente maior na metade basal do que na metade superficial das mucosas do antro e da cárdia. Todavia, na região do corpo houve uma equivalência numérica entre a população de células endócrinas na metade basal e na metade superficial da mucosa. Esse padrão de distribuição foi similar quando comparados os dois grupos de suínos, com e sem úlcera gástrica.

Segundo Bordi et al. (1989), na mucosa oxíntica humana as células endócrinas estão comumente localizadas no epitélio das glândulas gástricas, sendo pouco encontradas no istmo glandular, raramente nas fovéolas e ausentes na superfície do epitélio. Estas células possuem uma configuração fechada, sendo freqüente a ocorrência de prolongamentos citoplasmáticos. Estes aspectos coincidem com o observado no suíno.

Os resultados mostram que na região cárdica ocorre predomínio significativo de células argirófilas na região distal, em relação à região proximal $(p<0,05)$. Já na mucosa oxíntica observa-se, também, diferença estatística entre o número de células argirófilas das regiōes proximal e distal, todavia, com a densidade celular mais elevada no fragmento proximal $(p<0,05)$, o que revela um declínio gradual no sentido do antro. Com relação à mucosa antral, não se observou diferença significativa entre o número de células argirófilas localizadas nas regiões proximal e medial.

No homem, bem como em outros animais como o rato, observa-se aumento progressivo do número de células $\mathrm{G}$, que são argirófilas, nas regiões mais distais da mucosa antral em relação às proximais. Deve-se salientar que tanto no homem (Crivelli et al., 1977; Torres et al., 1986) como no suíno, as células $\mathrm{G}$ constituem-se na população endócrina mais 
freqüente da mucosa antral. A presença de úlcera na região da pars oesophagea não alterou a relação numérica destas células em nenhuma região do estômago.

As células argentafins foram mais freqüentes nas regiões basais da mucosa antral e oxíntica do suíno, como ocorre no homem e em outros animais estudados. Verificou-se, também, que a densidade de células argentafins no antro e no corpo gástrico de suínos é estatisticamente diferente. Resultados semelhantes foram obtidos no gato, por Kitamura et al., (1982), que, ao corarem as células argentafins pelo método de Masson-Hamperl, verificaram ser este tipo celular pouco numeroso, sobretudo na região do fundo, onde seu número era ainda menor do que na região pilórica. A presença de úlcera da pars oesophagea não alterou numericamente a densidade das células argentafins nas diferentes regiões da mucosa gástrica, semelhante ao que ocorreu em relação às células argirófilas.

O estudo da variação numérica das células argentafins dentro de uma mesma região demonstra que na região proximal da mucosa oxíntica ocorre população celular mais elevada

\section{Referências}

ALUMETS, J., HAKANSON, R., SUNDLER, F. Ontogeny of endocrine cells in porcine gut and pancreas: an immunocytochemical study. Gastroenterology, v. 85, p. 1359-1372, 1983.

BARBOSA, A. J. A., CASTRO,L. P. F., NOGUEIRA, A. M. M .F. A simple and economical modification of the Masson-Fontana method for staining melanin granules and enterochromaffin cells. Stain Technol., v. 59, p. 193-196, 1984.

BORDI, C, PILATO, F., CARFAGNA, G. et al. Argyrophil cell hyperplasia of fundic mucosa in patients with chronic atrophic gastritis. Digestion, v. 35, suppl. 1, p. 130-143, 1986.

BORDI, C., D'ADDA, T., BAGGI, M. T. et al. Structure and function of endocrine cells in the oxyntic (Acid-secreting) mucosa of human stomach. Scand.J.Gastroenterol., 24, suppl. 166, p. 115-121, 1989.

CALINGASAN, N. Y., KITAMURA, N., YAMADA, J. et al. Immunocytochemical study of the gastroenteropancreatic endocrine cells of the sheep. Acta Anat., v. 118, p. 171-180, 1984.

CRIVELLI, O., PERA, A., FERRARI, A. et al. G-cells counts in antral endoscopie biopsies by immunofluorescence. Scand.J.Gastroenterol., v. 12, p. 721-726, 1977.

EISSELE, R., BRUNNER, G., SIMON, B., etal. Gastric mucosa during treatment with lansoprazole. Helicobacter pylori is a risk factor for argyrophil cell hyperplasia. Gastroenterology, v. 112, n. 3, p. 707-717, 1997.

FRIERSEN, S. R., SCHIMKE, R. N., PEARSE, A. G. E. Genetic aspects of the Z-E syndrome. Prospective studies in two kindreds antral gastrin cell hyperplasia. Am. Surg., v. 176, p. 370-374, 1972.

GRIMELIUS, L. A silver nitrate stain for cells in human pancreatic islet. Acta Soc.Med.Ups.,v. 73, p. 243-270, 1968.

HUBER,W. G., WALLIN,R. F. Experimental production of porcine gastric ulcers. Vet. Med., v. 60, p. 551-558, 1965.

HUBER, W. G., WALLIN, R. F. Pathogenesis of porcine gastric ulcers. Am.J. Vet.Res., v. 28, p. 1455-1459, 1967.

INOKUCHI, H., KAWAI, K., TAKEUCHI, Y. et al. Immunohistochemical demonstration of EC cells in rat gastrointestinal tract. Histochemistry, v. 74, p. :453-456, 1982.

ITO, H., YAMADA, J., YAMASHITA, T. et al. An immunohisto chemical study on the distribution of endocrine cells in the gastrointestinal tract of the pig.Jpn.J.Vet.Sci., v. 49, p. 105-114, 1987. do que na região distal. Isto demonstra variações do número de células argentafins dentro de uma mesma região glandular, bem como variação similar dos diversos tipos de células endócrinas, uma vez que as células argirófilas da mucosa oxíntica, predominantemente células ECL, foram também mais frequentes na região proximal. Na mucosa antral não ocorreu variação do número de células argentafins entre as regiões proximal e medial.

Em trabalho prévio, Silva (dados não publicados) verificou que a densidade de células $\mathrm{G}$, a gastrinemia basal e pósestímulo e a concentração de gastrina em extrato de mucosa antral também não foram estatisticamente diferentes quando comparados os suínos com e sem úlcera gástrica. Considerando que a secreção clorido-péptica ocupa um lugar de destaque na gênese do processo ulcerativo da mucosa gástrica de suínos, esses resultados, mesmo que indiretamente, nos levam a supor que a úlcera em suínos pode também estar relacionada a desequilíbrios de fatores ligados à resistência da mucosa da pars oesophagea, além de prolongada exposição dessa mucosa ao suco gástrico

KITAMURA, N., YAMADA, J., YAMASHITA, T., et al. Endocrine cells in the gastrointestinal tract of the cat as revealed by various staining methods. Jpn.J.Vet.Sci., v. 44, p. 427-431, 1982.

KITAMURA, N., YAMADA, J., CALINGASAN, N. Y. et al. Immunocytochemical distribution of endocrine cells in the gastrointestinal tract of the horse. Equine Vet.J., v. 16, p. 103-107, 1984.

KITAMURA, N., YAMADA, J., CALINGASAN, N. Y. et al. Histologic and immunocytochemical study of endocrine cells in the gastrointestinal tract of the cow and calf. Am.J.Vet.Res., v. 46, p. 1381-1385, 1985.

KOKUE,EI.,VKUREBAYASHI,Y., SHIMODA,M. et al. Serial endoscopic observation of swine gastroesophageal ulceration induced by injection of a histamine-oil-beeswax misture. Am.J.Vet.Res.,v. 42, p. 1807-1810, 1981.

MAAROOS, H. I., HAVU, N., SIPPONEN, P. Follow-up of Helicobacter pylori positive gastrites and argyrophil cells pattern during the natural course of gastric ulcer. Helicobacter, v. 3, n. 1, p. 39-44, 1998

MAHAN, D. C., PICKETT, R. A., PERRY, T. W. et al .Influence of various nutritional factors and physical form of feed on esophagogastric ulcers in swine. J.Anim. Sci., v. 25, p. 10191023, 1966.

MAXWELL, C. V., REIMANN,E. N., HOEKSTRA, W. G. et al. Effect of dietary particle size on lesion development and on contents of various regions of the swine stomach. J.Anim.Sci.,v. 30, p. 911-922, 1970.

OMURA, N., KASHIWAGI, H., GANG, C. et al. Effect of pirenzepine on gastric endocrine cell kinetics during lansoprazole cadministration. J.Gastroenterol., v. 33, n. 5, p. 634-639, 1998.

POLAK, J. M., STAGG, B., PEARSE, A .G. E. Two types of ZollingerEllison syndrome, immunofluorescent, cytochemical and ultrastructural studies of the antral and pancreatic gastrin cells in different clinical states. Gut, v. 13, p. 501-512, 1972.

STAVE, R., BRANDTZAEG, P. Immunohistochemical investigation of gastrin producing cells ( $G$ cells). The distribution of $G$ cells in resected human stomach. Scand.J. Gastroenterol., v. 11, p. 705-712, 1976.

TORRES, A. J., ORTEGA, L., BLANCO, J. et al. Antral gastrin-producing G-cells and somatostatin-producing D-cells in peptic ulcer. Virchows Arch. A, v. 410, p. 165-171, 1986. 